\title{
Acetaldehyde alone may initiate hepatocellular damage in acute alcoholic liver disease
}

\author{
R E BARRY AND J D MCGIVAN \\ From the Departments of Medicine and Biochemistry, University of Bristol, Bristol
}

SUMmARY Acetaldehyde may be the injurious agent in acute alcoholic liver disease. It has been suggested that the mechanism of liver injury in this situation may be immunologically mediated. In the present study acetaldehyde has been bound to human liver plasma membranes. The activation of $\mathrm{C}_{3}$ by the acetaldehyde/membrane product was measured by immunofixation of the separated $\mathrm{C}_{3}$ components. Activation of $\mathrm{C}_{3}$ by acetaldehyde exposed liver plasma membranes was increased to $16.4 \%$ compared with $6 \%$ by non-exposed membranes $(p=0.004)$. Human liver plasma membranes bound $212 \pm 18 \mathrm{nmol}$ acetaldehyde per $\mathrm{mg}$ membrane protein. The binding constant was $439 \pm 81 \mu \mathrm{M}$. It is concluded that acetaldehyde bound to human liver plasma membranes activates the complement sequence and this may be the initial stage in the pathogenesis of acute alcoholic liver disease.

There are three major pathways for the metabolism of ethanol in the hepatocyte.

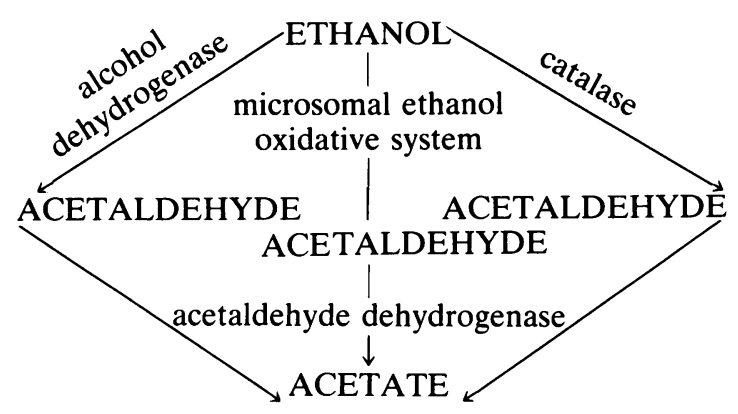

Whichever of these three metabolic pathways is used, acetaldehyde is the primary metabolic product of ethanol. High circulating concentrations of acetaldehyde are found in the serum in alcohol abuse. $^{2}$ It may be therefore that acetaldehyde, rather than alcohol itself, is the injurious factor in alcoholic liver disease. We have recently shown that acetaldehyde binds to the plasma membranes of rat liver cells. ${ }^{3}$ At concentrations of acetaldehyde up to $10 \mathrm{mM}$ this binding does not affect cellular metabolism as measured by urea synthesis or gluconeogenesis. Similarly, gross membrane function, as assessed

Address for correspondence: Dr R E Barry. Department of Medicine, Bristol Royal Infirmary. Bristol BS2 8HE.

Received for publication 15 November 1984 by alanine transport or lactate dehydrogenase leakage, was not influenced by the binding of acetaldehyde to the membrane. These findings are therefore consistent with the hypothesis that any injurious effect of acetaldehyde may be mediated by an immune response rather than by a direct toxic effect on metabolism. In the present study we examine this possibility by measuring the binding of acetaldehyde to human liver plasma membranes and studying the effect of this binding on complement activation.

\section{Methods}

BIOPSIES

Wedge hepatic biopsies were obtained from patient volunteers who gave informed consent and whose livers were being exposed during the course of surgical treatment of non-hepatic disease. The liver biopsies were immediately homogenised at $0-4^{\circ} \mathrm{C}$ and plasma membrane vesicles were prepared by a method slightly modified from that of van Amelsvoort, Sips, and Van $\mathrm{Dam}^{4}$ by high speed centrifugation on a discontinuous sucrose gradient made up from $46.5 \%$ sucrose and $21.5 \%$ sucrose.

The purity of the liver plasma membrane vesicle preparations was assessed by measuring the enzyme markers, 5-nucleotidase and glucose-6-phosphatase.

The activation of the third component of complement $\left(C_{3}\right)$ by membranes exposed to acetaldehyde was measured as follows: human liver plasma mem- 
brane vesicles containing approximately $0 \cdot 1 \mathrm{mg}$ protein were incubated in $100 \mathrm{mM}$ Hepes buffer at $\mathrm{pH} 7.4$ and $37^{\circ} \mathrm{C}$ for $60 \mathrm{~min}$. The test membranes were incubated in the presence of $1 \mathrm{mM}$ acetaldehyde. Control membranes were incubated in the absence of acetaldehyde. The membranes were then harvested by centrifugation and washed three times in cold Hepes buffer to remove any free acetaldehyde. Both the test and the control membranes were then separately incubated in human serum for 30 minutes at $37^{\circ} \mathrm{C}$. After incubation the mixtures were centrifuged and EDTA added to the supernatant serum to a final concentration of $0.01 \mathrm{M}$ to abolish any further activation of $\mathrm{C}_{3}$.

The sera which had been exposed to the membrane preparations were then layered onto a $1 \mathrm{~mm}$ thick $1 \%$ agarose gel made up in 0.06 molar barbitone buffer $\mathrm{pH} 8 \cdot 6$. The gel also contained $0 \cdot 01$ $M$ EDTA to prevent any activation of $\mathrm{C}_{3}$ during electrophoresis. Electrophoresis was carried out for 40 minutes at 10 volts $/ \mathrm{cm}$ with cooling. This separates the native component of $\mathrm{C}_{3}$ from the activated components of $\mathrm{C}_{3}$ (Fig. 1). The native and activated components were precipitated in the gel by layering on the gel a cellulose acetate membrane which had been soaked in the specific anti-human $\mathrm{C}_{3}$ (Atlantic Antibodies, Scarborough, Me, USA). The gels were then soaked in hypertonic saline overnight which washes out all of the non-immunoprecipitated proteins leaving only the $\mathrm{C}_{3}$ components in the gel. The gel was then dried in a stream of warm air and stained with Page blue. The density of the $C_{3}$

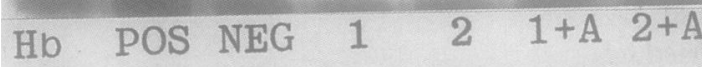

Fig. 1 Agarose gel in which electrophoresed sera have been immunoprecipitated with specific anti-human $C_{3}$. Pos $=$ Positive control. . Human serum allowed to stand for 24 hours at room temperature to activate the $C_{3}$. The thick, lower band is native $C_{3}$. The upper band is activated $C_{3}$. Neg $=$ Negative control. Human serum from the same patient as the positive control but placed immediately in EDTA to prevent activation of $C_{3}$. There is no band in the position of activated $C_{3} .1$ and $2=$ Sera in which liver plasma membranes from two different human livers have been incubated. Slight activation of $C_{3}$ can be seen. $1+A$ and $2+A=$ Sera in which the same liver plasma membranes (as in 1 and 2 respectively) have been incubated but here the plasma membranes had been pre-incubated in buffer containing $1 \mathrm{mM}$ acetaldehyde. Increased activation of $C_{3}$ is clearly visible. $\mathrm{Hb}=$ Marker. components was measured using an integrating densitometer.

The binding of acetaldehyde to human liver cell plasma membrane vesicles was measured using the incorporation of tritium from tritiated sodium cyanoborohydride as described previously. ${ }^{6}$

\section{Results}

Table 1 gives an indication of the purity of the preparation of human liver plasma membranes by this method. The figures indicate that the preparation results in a six-fold concentration of plasma membranes compared with the whole liver homogenate. The purity of the preparation is comparable with that obtained by others in the literature using the same preparative technique. ${ }^{4}$ There is significant contamination of the plasma membrane preparation by endoplasmic reticulum. Further purification of the plasma membranes would require a continuous density gradient, the facilities for which are beyond the resources of this laboratory, and the small yield of such highly purified membranes from a single human wedge liver biopsy is likely to preclude $\mathrm{C}_{3}$ activation studies.

Acetaldehyde bound to the human liver plasma membranes (Fig. 2) according to the following parameters:

Amount bound $=212 \pm 18 \mathrm{nmol} / \mathrm{mg}$ membrane protein (SEM).

The binding constant was $439 \pm 81 \mu \mathrm{M}$.

Figure 3 illustrates the method used for quantitating the $\mathrm{C}_{3}$ activation measured by the immunofixation technique described.

Experiments were undertaken on membrane preparations from five human livers. The results are shown in Table 2.

$\mathrm{C}_{3}$ activation by the membranes alone (control membranes) was $6.6 \% \pm 2 \%$. When the membranes

Table 1 Purity of human liver plasma membrane preparation

\begin{tabular}{|c|c|c|c|}
\hline & $\begin{array}{l}\text { Whole } \\
\text { liver } \\
\text { homogenate } \\
\text { ( } \text { emol/h/mg } \\
\text { protein) }\end{array}$ & $\begin{array}{l}\text { Plasma } \\
\text { membrane } \\
\text { preparation } \\
\text { ( } \text { emol/h/mg } \\
\text { protein) }\end{array}$ & $\begin{array}{l}\text { Purifica- } \\
\text { tion }\end{array}$ \\
\hline $5^{\prime}$-nucleotidase & $5 \cdot 2$ & 30 & $\times 5 \cdot 8$ \\
\hline Glucose-6-phosphatase & $4 \cdot 3$ & $5 \cdot 8$ & $\times 1 \cdot 3$ \\
\hline
\end{tabular}

$5^{\prime}$-nucleotidase is a marker for liver plasma membranes. Glucose-6-phosphatase is a marker for smooth endoplasmic reticulum. The figures indicate a good preparation of liver plasma membranes with a slight contamination by smooth endoplasmic reticulum. 


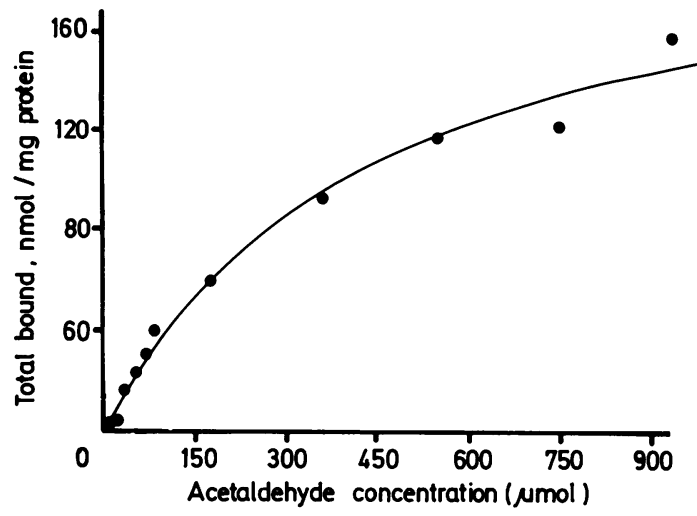

Fig. 2 Binding of acetaldehyde to liver cell membranes is concentration dependent as shown. Membranes were prepared from the livers of three normal volunteers.

from the same liver preparations were pre-exposed to acetaldehyde as described (test membranes) $\mathrm{C}_{3}$ activation rose three-fold to $16.4 \% \pm 1.8 \%$. This increase is significant at the level $\mathrm{p}=0.004$ (paired $t$ test).

\section{Discussion}

The liver cell plasma membranes prepared by this method are vesicular. Previous studies indicate that plasma membrane vesicles prepared by this method are mainly correctly orientated - that is, external plasma membrane surface outwards. The vesicular structure, however, may well be lost during the subsequent incubation thus exposing the serum complement to the internal surface of the liver plasma membranes, which may activate the complement sequence to some extent.

As with clotting factors, the complement system is unstable in vitro so that some spontaneous activation of $\mathrm{C}_{3}$ does occur $(6 \%$ in the simultaneous control incubations). The increased activation which results from the pre-exposure of the plasma membranes to acetaldehyde is, however, highly significant.

The concentration of acetaldehyde used in the studies of complement activation was selected to be $1 \mathrm{mM}$. Dose response studies were not possible because such studies require large amounts of plasma membrane preparations. The availability of human liver from which such preparations could be made was, of course, limited by ethical as well as clinical considerations. The concentration of acetaldehyde in the systemic circulation in alcohol abuse is significantly less than $1 \mathrm{mM}$ but there are no data on the intrahepatic concentrations of acetaldehyde which may be achieved during alcohol

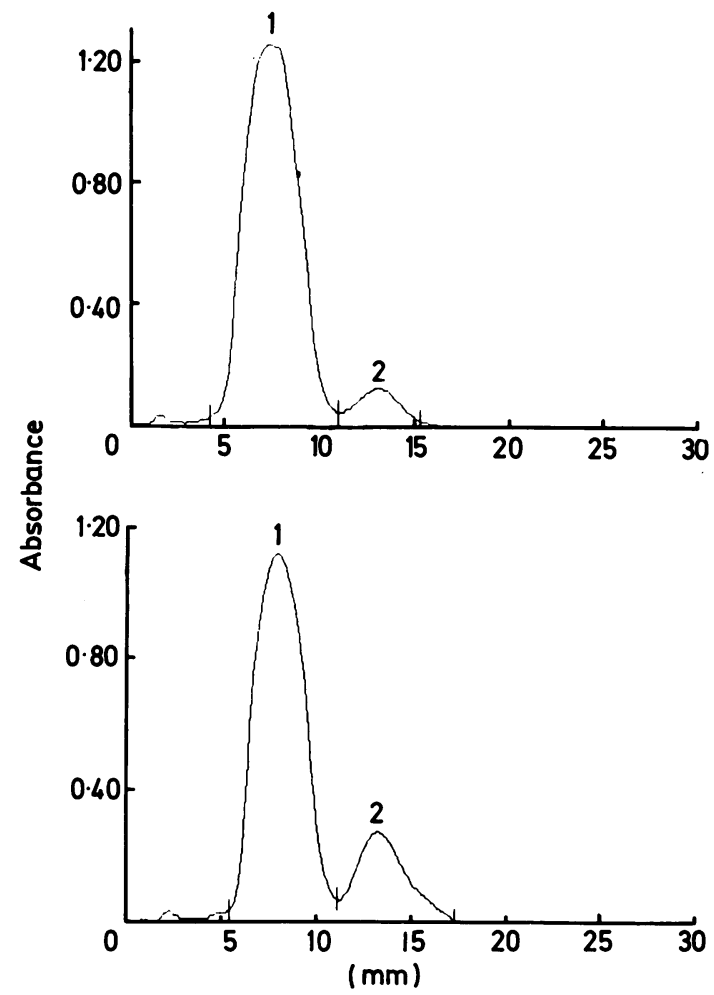

Fig. 3 Upper trace shows the two peaks of a densitometric scan from sera incubated with liver plasma membranes. Peak 1 is native $C_{3}$ (corresponds to the lower bands in Fig. 1). Peak 2 is activated $C_{3}$ (upper bands of Fig. 1). Amount of total $C_{3}$ in serum is given by the sum of areas under peaks $1+2$. Amount of activated $C_{3}$ is given by area under Peak 2. Percentage activation $=$ area $2 /($ area $1+$ area 2$) \%$. Lower trace shows densitometric scan of sera incubated with the same liver plasma membranes but which had been pre-incubated with $1 \mathrm{mM}$ acetaldehyde. Area of peak 2 (activated $C_{3}$ ) is significantly increased.

Table 2 Mean activation of $C_{3}$ as percentage of total $C_{3}$ in serum

\begin{tabular}{|c|c|c|c|}
\hline & $\begin{array}{l}\text { Control } \\
\text { membranes }\end{array}$ & $\begin{array}{l}\text { Acetaldehyde } \\
\text { exposed } \\
\text { membranes }\end{array}$ & $\begin{array}{l}\text { Experi- } \\
\text { ments } \\
\text { (no) }\end{array}$ \\
\hline Patient 1 & $12 \cdot 6 \%$ & $18 \cdot 5 \%$ & 2 \\
\hline Patient 2 & $5 \cdot 3 \%$ & $8.8 \%$ & 3 \\
\hline Patient 3 & $3.2 \%$ & $16.0 \%$ & 7 \\
\hline Patient 4 & $6.6 \%$ & $21 \cdot 3 \%$ & 3 \\
\hline Patient 5 & $4 \cdot 3 \%$ & $17.9 \%$ & 5 \\
\hline $\begin{array}{l}\text { Total mean } \\
\text { activation } \pm \text { SEM } \\
\text { (all experiments) }\end{array}$ & $6 \cdot 6 \pm 2 \cdot 03$ & $16 \cdot 4 \pm 1 \cdot 77$ & 20 \\
\hline
\end{tabular}


abuse. As the binding constant for acetaldehyde on the plasma membranes was shown to be approximately $440 \mu \mathrm{M}$, the concentration of acetaldehyde for the complement activation experiments, for which dose dependency studies could not be done, was chosen to be approximately twice the binding constant. At this concentration the binding sites on the plasma membranes might be expected to be saturated thus any effect on complement activation ought to be detected.

Previous experiments had indicated that $1 \mathrm{mM}$ free acetaldehyde would cause an activation of $\mathrm{C}_{3}$ of approximately $5 \%$. The thorough washing of the plasma membranes after incubation with acetaldehyde is, however, more than sufficient to remove any unbound acetaldehyde remaining. But if a small trace of free acetaldehyde were to have been carried over with the plasma membranes, in spite of the washing procedure, into the complement containing incubation medium, then this clearly would not be of sufficient concentration to account for the three-fold increase in $\mathrm{C}_{3}$ activation noted in these experiments.

The non-enzymic adduction of acetaldehyde to rat liver cell plasma membranes had previously been demonstrated. $^{36}$ The experiments reported here indicate that acetaldehyde will also bind to the plasma membranes of normal human liver cells via the formation of an intermediate Schiff base. Although our experiments do not exclude other effects of acetaldehyde on membrane function such as fluidity, or on membrane enzymes such as adenyl cyclase, our experiments in rats $^{3}$ show that the binding of acetaldehyde to the liver plasma membranes does not affect hepatic function assessed by urea synthesis and gluconeogenesis nor gross membrane function assessed by alanine transport. This finding is compatible with the hypothesis that any injurious effect of acetaldehyde may be mediated by an immune mechanism. The histological picture of the liver in acute alcoholic liver disease in man is, however, quite unlike the histological picture in, for example, primary biliary cirrhosis or chronic active hepatitis which are thought to be immunologically mediated. In these two diseases the cellular infiltrate is located predominantly in the portal tracts and consists mainly of lymphocytes and plasma cells. These histological features are compatible with a cell mediated immune mechanism in the pathogenesis of these diseases. By contrast, in acute alcoholic liver disease the cellular infiltrate is lobular in distribution and consists mainly of polymorphonuclear cells. Thus, although lymphocyte sensitisation has been shown to both acetaldehyde ${ }^{8}$ and Mallory's hyaline, ${ }^{9}$ the histological pattern of acute alcoholic liver disease is more suggestive of antibody mediated cytotoxicity. Neuberger et al $^{10}$ have recently presented evidence of circulating antibodies in the serum of patients with alcoholic liver damage against alcohol altered rabbit liver cells. The experiments reported in the present paper, however, indicate that liver cell membranes to which acetaldehyde has been bound will activate the third component of complement in human serum in the absence of antibody.

Complement is a series of proteins which can be activated in sequence to produce terminal active component that causes cell lysis. This cascade of activation of the sequential components may be initiated by the classical or the alternate pathway. Either pathway results in the activation of $\mathrm{C}_{3}-$ the major component of the complement system in the serum. The finding that the plasma membranes of liver cells after exposure to acetaldehyde will active $\mathrm{C}_{3}$ may therefore indicate that this could be the mechanism by which liver cell damage may be initiated in acute alcoholic liver disease, even though presently available analytical techniques have so far failed to demonstrate convincingly any evidence of complement activation in alcoholic liver disease in vivo.

Although complement is classically activated by the complexing of antibody with antigen, the presence of antibody is not essential. Complement may be activated by molecular surface charge or by the surface properties of some proteins. ${ }^{11}$ Subtle changes in the protein's surface properties may influence the molecule's ability to activate complement. ${ }^{12}$ It has previously been suggested ${ }^{13}$ that the binding of acetaldehyde to hepatocyte plasma membranes may activate the complement sequence by causing a structural change in the surface of the plasma membrane. This paper presents experimental evidence to indicate that such a mechanism can occur.

If $\mathrm{C}_{3}$ activation by the acetaldehyde/membrane product is the mechanism which initiates liver damage in acute alcoholic liver disease, then the antibodies shown by Neuberger and coworkers ${ }^{10}$ may be a secondary phenomenon and progression to cirrhosis may perhaps occur as a result of similar immunological sensitisation as suggested by Perperas and colleagues. ${ }^{14}$

\section{References}

1 Peters TJ. Ethanol metabolism. Br Med Bull 1982; 38: 17-20.

2 Korsten MA, Matsuzaki S, Feinman L, Lieber CS. High blood acetaldehyde levels after ethanol admin- 
istration. Difference between alcoholic and nonalcoholic subjects. $N$ Engl J Med 1975; 292: 386-9.

3 Barry RE, McGivan JD, Hayes M, Read AE. Acetaldehyde is not directly hepatotoxic in alcoholic liver disease. Clin Sci 1983; 65: 23p.

4 van Amelsvoort JMM, Sips HJ, Van Dam K. Sodium dependent alanine transport in plasma membrane vesicles from rat liver. Biochem J 1978; 174: 1083-6.

5 Barry RE, McGivan JD, Hayes M. Acetaldehyde binds to liver cell membranes without affecting membrane function. Gut 1984; 25: 412-6.

6 Whicher JT, Higginson J, Riches PG, Radford S. Clinical applications of immunofixation, detection and quantitation of complement activation. J Clin Pathol 1980; 33: 781-5.

7 Sips HJ, Brown D, Oonk R, Orci L. Orientation of rat liver plasma membrane vesicles. A biochemical and ultra structural study. Biochem Biophys Acta 1982; 692: 442-54.

8 Actis GC, Ponzetto A, Rizzetto M, Verme G. Cell mediated immunity to acetaldehyde in alcoholic liver disease demonstrated by the leucocyte migration test. Am J Dig Dis 1978; 23: 883-6.
9 Zetterman RK, Luisada-Opper A, Leevy CM. Cell mediated immune response to alcoholic hyaline. Gastroenterology 1976; 70: 382-4.

10 Neuberger J, Crossley IR, Saunders JB et al. Antibodies to alcohol altered liver cell determinants in patients with alcoholic liver disease. Gut 1984; 25: 300-4.

11 Thompson RA, Ross IN, Coneybeare BJ. The significance of $\mathrm{C}_{3}$ breakdown products in fresh plasma. In: Opferkuck W, Rother K, Schulz DR, eds. Clinical aspects of the complement system. Stuttgart: George Thieme, 1976: 27-31.

12 Kazatchkine MD, Fearon DT, Austen KF. Human alternative complement pathway: membrane-associated sialic acid regulates the competition between $\mathrm{B}$ and $\beta \mathrm{IH}$ for cell bound $\mathrm{C}_{3} \mathrm{~b}$. J Immunol 1979; 122: 75-81.

13 Barry RE. The pathogenesis of hepatitis in alcohol abuse and jejunoileal bypass. Lancet 1983; 2: 489-90.

14 Perperas A, Tsantoulas D, Portman B, Eddleston ALWF, Williams R. Autoimmunity to a liver membrane lipoprotein and liver damage in alcoholic liver disease. Gut 1981; 22: 149-52. 